\title{
Asking is not enough. A research study on teaching qualitative interviews in Italy
}

\section{Pretto, Albertina}

Department of Sociology and Social Research, University of Trento, Italy

\begin{abstract}
In the area of social research, it is not uncommon to come across qualitative interviews (transcribed or recorded) that present conduction strategies which seem to be in contrast to that is recommended by the literature on this subject. In order to understand the reason why this occurs, I present the results of a research carried out among Italian sociologists who use qualitative interviews for their research; I try to establish a connection between the conduction strategies used by researchers and their training. I found three different conducting styles, and divided my interviewees into three categories. But, only one of these categories presents a real positive attitude towards qualitative interviews. The problem is that all these researchers also teach qualitative methods at University or train new interviewers for their research and they pass down their same attitude to their students, for better or worse.
\end{abstract}

Keywords: qualitative interviews; conducting styles; teachers. 


\section{Introduction}

In Italy, the qualitative research has become established in social sciences only in the recent decades, since making its way in the national scientific area has been hindered for a long time by different factors: hostility from fascism, reluctance on the part of dominant philosophical positions, the prevailing quantitative research (Gobo, 2008). Italian sociologists' attention turned towards qualitative research methods only at the end of the 70 s and the reasons for this interest were both theoretical - due to the interest in the centrality of the subject and in the motivations behind people's actions - as well as technical-methodological, due to the 'seeming simplicity' of these approaches to research (Campelli, 1990). Notwithstanding, in the Italian Sociology, the stereotype of the nonscientific nature of qualitative method lingered and those methods were continuously excluded from courses on methodology, also because of the education and approach of the sociologists of that time (Gobo, 2008). In Italy, the first Department of Sociology (then Faculty of Sociology) was established in Trento in 1962 and those who taught there did not get a specific sociological background, because they studied other disciplines, such as Philosophy, Law, Political Science, Economy, Statistic; moreover, it should be considered that, in Trento - which has been for a long time the only University with a Department of Sociology in Italy - specific sociological courses were only $30 \%$ of the total course until the 80s (Gubert \& Pollini, 2015). The academics with a background on Economy or Statistic humanities tended to teach methodological courses in which qualitative methods were not explained or adopted (Gobo, 2008; Gubert \& Pollini, 2015). Those who carried on research with qualitative methods were autodidacts and had meagre support also from literature, since textbooks on qualitative methods written by Italian sociologists did not exist and those written by foreign academics and translated in Italian were scarcely available: unless one knew English (not so common language in Italy in that time), books on methodology attainable until the 80s were on statistics and quantitative methods (Gobo, 2008). Only since the end of the 90s, the Italian academic community created specific programs of study within degree and $\mathrm{PhD}$ courses, and institutionalized several schools of high training on qualitative methods (Pretto, 2011).

Despite this long and difficult path, qualitative methods and teaching them face to this day obstacles and prejudices: in many academics' current opinion, besides obviously acquiring a command of sociological theory, students should develop their skills first of all to deal with quantitative data, for instance, to know what the unemployment or aging rate is, to understand the data shown in a table and then be able to analyze second-level data (Pretto, 2015a). These are all fundamental skills; no one questions that. However, following this point of view, to be able to observe, to listen, and to interview through qualitative techniques seem to be skills to which little importance is attached (Becker, 1998). All these aspects, unfortunately, has generated - in Italy but not only - some 'distorted' attitudes: for 
instance, regarding teaching and using qualitative interviews, some sociologists still believe that to carry out research and obtain information from people, 'asking' is enough (Kellehear, 1993) and this is an error which sometimes is taught to students and/or young researchers. On the contrary, a good training should be provided to the latter by their teachers, in order that they acquire the correct attitude and the skills necessary to gather good interviews and to avoid making mistakes (Lindlof \& Taylor, 2011; Roulston, deMarrais \& Lewis, 2003). Some authors describe as mistakes to ask lengthy questions or yes/no questions, to over-lead the participant, failing to pursue emergent references during the interview, to over-direct the narrative preventing the interview plot from developing, talking too much stifling the interviewee and so on (deMarrais, 2004; Gesch-Karamanlidis, 2015; Myers \& Newman, 2007). Throughout my career, I have actually read more than a few transcripts of interviews that surprised or embarrassed me for the lack of respect or attention on the part of the interviewer towards the interviewee. The excerpt below, for example, shows how the interviewer 'imposed' a topic which had not yet emerged from the conversation on an interviewee and that woman was a possible victim of domestic violence.

Interviewer: "Now, tell me about your relationship with your husband..."

Mrs T.: "What do you mean?"

Interviewer: "You know what I mean. Tell me about your husband: how does he treat you?"

So, in some cases, the interviewer's behavior contrasts with the main guidelines on conducting a qualitative interview, such as kindness, respect, careful listening, receptiveness, a nonjudgmental attitude, empathic comprehension and so on (see e.g. Denzin \& Lincoln, 2017; Leavy, 2014; Saldana, 2016). In this way, they produce interviews of poor quality making mistakes that negatively impact the data collection process.

Then, the question is: why does the behavior of some researchers and young interviewers differ so much from what is recommended even in the most common methodology textbooks? Taking into account that in Italy all researchers who work at the University are compulsorily also lecturers, might an erroneous attitude in gathering qualitative interviews depend on lack of training or on the attitude itself of those who teach?

\section{Research design}

I have not found any Italian studies focused on this topic so, I would aim to answer to this question trough this research and trying to establish a connection between the teachers and interviewers' training and the strategies they adopt in collecting qualitative interviews. 
At the beginning of my study, I asked, obtained and read transcriptions of qualitative interviews collected for different research projects by a number of interviewers (who differ according to age, academic position and training). Then, I contacted and interviewed some of the interviewers who surprised me with the strategy of interview conduct they had adopted, both in a positive and in a negative way. I also interviewed professors and researchers who were responsible for the project concerned.

I interviewed 28 people: I collected 6 récits de vie (Bertaux, 1998) of experienced professors and/or researchers with a strong academic background in Italian universities. I selected this group through personal knowledge of their qualitative research works or upon advice of other members of the academic community. I also collected 4 récits de vie of their students/interviewers.

Due to time constraint, I have conducted 18 more semi-structured interviews with questions focusing on the main areas of interest (training and experience in qualitative interviews and research, training in the conduction of qualitative interviews, attitude towards the interviewees). Of this group of interviews, 10 concerned the interviewers and 8 involved professors and/or expert researchers. Of this latter group, 6 were professors and/or researchers who do not conduct interviews personally but rely on interviewers.

I also collected opinions and thoughts of professors, researchers and students/interviewers in informal conversations during national meetings or conferences.

In the analysis phase, for every interview, I tried to find and examine information and indexes concerning the interviewees' cultural and professional background in qualitative methods, their relationship with their teachers and/or other significant trainers and their attitude towards people they interview.

\section{Findings}

As I examined all this material, three different conducting styles came to light, which allowed me to create three categories that I defined as second choice qualitative interviewers, qualitative-quantitative interviewers and authentic qualitative interviewers.

I have defined the first group as second choice qualitative interviewers just because it seems that they have chosen qualitative research as their second choice.

Ms F.: “... you might find yourself in front of a mythomaniac, or of people who have been in psychological analysis for years, and are therefore veterans, professionals of narration, and you have to pretend you're interested in what they are saying and you wait for something interesting to be said to you..." 
Mr P.: "The point is that I don't have the ability to do quantitative research, so I started working with qualitative inquiries which are easier ...',

Often they did not study quantitative research techniques and therefore, without any training in Statistics, they thought that qualitative research was the lifeline that allowed them to carry out their studies anyway. They often have a negative attitude towards the interviewees: as researchers, they feel superior and usually have the same way of relating to them. They take what is offered and then blame the interviewees when the narration is not satisfactory for the research goal. These researchers/interviewers have never mentioned the great importance of listening and it seems they fail to establish any relationship with the narrator.

The second group is that of the qualitative-quantitative interviewers: they have received good training in quantitative techniques, but - throughout their career - they have also understood the value and importance of research carried out through qualitative methods.

Mr I.: "I don't do them [qualitative interviews] because it takes too much time and I don't have enough patience... I send my students to collect them and I'm not strict about the conducting strategy, they can do whatever they want as long as they bring back the things we need..."

Ms L.: "I'm a hard methodologist; I must make them talk, take about what I need. If I see that they aren't telling me what I want, after a while, I ask them directly. I can't stay there for hours and hours, and possibly for nothing, because, you see, some people are redundant and need many more words than others who tell you the same thing with few words..."

However, although they discovered the intrinsic value of qualitative interviews, they conduct the latter as if they were carrying out a survey using a questionnaire: they ask their questions in such a direct and formulaic manner, that it sometimes seems that they are simply unable to listen to the narrator's words. They don't consider the relationship with the interviewees as an important element for the interview and they are not interested in deepening the discussion with them. When I was listening to these researchers/interviewers, I had the impression that they were used to maintaining a very detached relationship with the interviewees. The interviews they conduct this way are very accurate, but in the end they are meaningless in many cases because the implicit and explicit motivations of the interviewees are lost, as there is no interactive process.

I have defined the last group as authentic qualitative interviewers: they can be considered natural-born listeners.

Ms B.: "A good interviewer [...] is a person who is curious about the other, one who can grasp in the other's talk all the right elements and new subjects 
to introduce. It is therefore a person who, on the one hand, has a human characteristic, the ability to comprehend the other; and, on the other hand, on the scientific side, has the ability to recognize the areas of meaning of the interviewee..."

Mr B.: "During a face-to-face interview, you must remember that you are both a researcher and a human being. You see, in my opinion, when you rely on the qualitative approach [...] the depth of the discussion is essential, and I'm not referring to research only, but to the human and personal side as well..."

They make the interviewees feel at ease, they respect their silences and they try to interpret, rather than to force them. If the narrator doesn't want to discuss a certain topic, for instance, they make a note on the perception of their discomfort. They combine respect for the person with the objective detachment, without being cold. Many of these researchers/interviewers have received proper training in quantitative techniques, and they use it when necessary for their studies; however, they have chosen qualitative research, often learning its techniques on their own because there were not specific courses on qualitative methods when and where they went to university.

So, what has emerged from my study, is that only people belonging to this last group rely on proper qualitative methods.

I suppose there can be different reasons to explain why so many researchers use qualitative techniques the wrong way but, in my opinion, one of these reasons is that many of them had not received proper training. And the lack of training in qualitative methods is a sore point in the Italian academic community (and not only): as I wrote above, until the 90s, qualitative research played a minor role in Italy compared to quantitative research and it is only in the last twenty years that the Italian academic community created specific programs of study within degree and $\mathrm{PhD}$ courses, and institutionalized several schools of high training on qualitative methods. So, people I interviewed that were over 45 (more or less) openly stated that they have never received any practical training. All that they have learned, was the result of personal effort. Only the youngest said they had participated in some specific training course or specialization schools.

I must add that, unfortunately, in Italy quantitative research is still considered more 'scientific' and is commissioned more often by government institutions and by other agencies, which allocate more funds to it. Quantitative data still prevails in respect of qualitative data (Gobo, 2008; Silverman, 2000) and qualitative researchers are still considered soft scientists (Pretto, 2015b). 
This background allows us to better understand the attitude of the qualitative-quantitative interviewers, the second group: they don't want to leave the quantitative approach because they find it reassuring and because it increases their credibility in the scientific community also when they use qualitative techniques.

On the other hand, I am not able to find any justification for the behavior of the researchers of the first group, the second choice qualitative interviewers.

\section{Brief discussion and conclusion}

As I wrote before, according to Italian norms, every academic working in a university must also teach. Each researcher or professor must teach in one or more courses. Thus, all academics I interviewed were also teachers, oftentimes of Methodology courses which are more or less focused on qualitative methods. But what kind of teaching can the academics of the first two groups give to their students? And the answer is that they pass down their same attitude.

As a matter of fact, in the excerpts above, the second quote is always of a former student of the academic who stated the first quote. In fact, younger researchers and 'simple interviewers' that I interviewed, were former students of such academics and they presented an attitude similar to that of their masters, for better or worse. But some of these current interviewers will probably be tomorrow's researchers and teachers (if they work at the Italian universities). So, if we want to have good qualitative researchers and teachers tomorrow, we have to be good teachers right now.

To conclude, since I have not found other studies on this specific topic, I believe that it would be interesting and worthwhile to Social Sciences in general to conduct more research of this kind, in order to verify the state of the art of qualitative research. I think that it would be useful to investigate the ways in which qualitative methods are applied to contribute to this debate and to disseminate best practice in teaching.

\section{References}

Becker, H. (1998). Tricks of the Trade. Chicago, IL: Chicago University Press.

Bertaux, D. (1998). Les Récits de vie. Paris, France: Editions Nathan.

Campelli, E. (1990). Le storie di vita nella sociologia italiana: un bilancio. Sociologia e Ricerca Sociale, 31, 179-195.

deMarrais, K. (2004). Qualitative interview studies: Learning through experience. In K. deMarrais \& S. D. Lapan (Eds.), Foundations for research (pp. 51-68). Mahwah, NJ: Erlbaum. 
Denzin, N. Y., \& Lincoln, Y. S. (2017). The SAGE handbook of qualitative research (5th edition). Thousand Oaks, CA: SAGE Publications Inc.

Gesch-Karamanlidis, E. (2015). Reflecting on Novice Qualitative Interviewer Mistakes. The Qualitative Report, 20(5), 712-726.

Gobo, G. (2008). Con giustificato ritardo. La nascita della sociologia in Italia. In D. Silverman, Manuale di ricerca sociale e qualitativa (pp. I-XVII). Rome, Italy: Carocci.

Gubert, R., \& Pollini, G. (2015). L'evoluzione della formazione sociologica. In A. Perino \& L. Savonardo (Eds.), Sociologia, professioni e mondo del lavoro (pp. 105-125). Milano, Italy: Edizioni Egea.

Kellehear, A. (1993). The unobtrusive researcher: A guide to methods. St Leonards, NSW: Allen and Unwin.

Leavy, P. (2014). The OXFORD handbook of qualitative research. New York, NY: Oxford University Press.

Lindlof, T. R., \& Taylor, B. C. (2011). Qualitative communication research methods (3rd ed.). Thousand Oaks, CA: Sage.

Myers, M. D., \& Newman, M. (2007). The qualitative interview in IS Research: Examining $\begin{array}{llll}\text { the } \quad \text { Information and } & \text { Organization, } 26 .\end{array}$ doi:10.1016/j.infoandorg.2006.11.001

Pretto, A. (2011). Italian Sociologists' approach to qualitative interviews. Bulletin of Sociological Methodology/ Bulletin de Methodologie Sociologique, 112(1), October 2011, pp. 71-83.

Pretto, A. (2015a). Professione sociologo: quale possibile formazione per il futuro? In A. Perino \& R. Savonardo (Eds.), Sociologia, professioni e mondo del lavoro (pp. 141152). Milano, Italy: Edizioni Egea.

Pretto, A. (2015b). Sociólogos numerólogos. In A. Marradi (Ed.), Las ciencias sociales ¿seguirán imitando a las ciencias duras? Un simposio a distancia (pp. 239-244). Buenos Aires, Argentina: Editorial Antigua.

Roulston, K., deMarrais, K., \& Lewis, J. B. (2003). Learning to Interview in the Social Sciences. Qualitative Inquiry, 9(4), 643-668. doi: 10.1177/1077800403252736

Saldana, J. (2016). The Coding Manual for qualitative researchers. 3rd edition. London, UK: Sage Publications Ltd.

Silverman, D. (2000). Doing Qualitative Research: A Practical Handbook. London, UK: Sage Publications Ltd. 